\title{
Diversity, Incidence and Severity of Mistletoe on Cocoa (Theobroma Cacao) in Kumba, Meme Division, Southwest Region, Cameroon
}

\author{
Oben Tom Tabi ${ }^{1,2, *}$, Pierre Haiwe ${ }^{2}$, Egbe Andrew Enow ${ }^{1,3}$ \\ ${ }^{1}$ Faculty of Agriculture and Veterinary Medicine, University of Buea, Buea, Cameroon \\ ${ }^{2}$ Department of Agriculture, Higher Technical Teachers' Training College, Kumba, Cameroon \\ ${ }^{3}$ Faculty of Science, University of Buea, Buea, Cameroon
}

Email address:

obentomtabi@yahoo.com (O. T. Tabi)

${ }^{*}$ Corresponding author

\section{To cite this article:}

Oben Tom Tabi, Pierre Haiwe, Egbe Andrew Enow. Diversity, Incidence and Severity of Mistletoe on Cocoa (Theobroma cacao) in Kumba, Meme Division, Southwest Region, Cameroon. American Journal of Agriculture and Forestry. Vol. 9, No. 4, 2021, pp. $219-226$. doi: 10.11648/j.ajaf.20210904.18

Received: June 22, 2021; Accepted: July 5, 2021; Published: July 15, 2021

\begin{abstract}
Cocoa is an important cash crop grown in about 400,000 ha in Cameroon and its yield remains low in spite of the use of elites' varieties. Mistletoes are the main production limitation factor. Ecology and diversity of mistletoe are yet to be investigated in some major cocoa production areas of Cameroon. This study aimed to identify the mistletoe species infecting this crop, determine their incidence, severity and distribution, evaluate their possible sources of infection from farmers' perspectives in the Kumba locality and appropriate management practices for these parasites. A survey was carried out in 2018, whereby samples of mistletoe on 9-17 years old cocoa plants were collected from 30 farms in 10 villages within the Kumba environs. Voucher specimens were taken for identification at the Limbe Botanic Gardens. A total of 7,279 plants were examined randomly in 3 farms per village and data obtained, analyzed using descriptive analysis and ANOVA. Three mistletoe species were identified: Phragmanthera lapathifolia, Phragmanthera batangae, and Tapinanthus globiferus. All the 10 villages surveyed, were infested with either of the parasites with Kake I having the highest incidence of $43.11 \%$ and with all the mistletoe species. Phragmanthera lapathifolia the most abundant $(21.43 \%)$ of the 2,290 plants were infested. ANOVA at $(P$ $=.01 ; .05$ ) showed that the local cocoa variety, Forastero was significantly susceptible than the hybrid, Trinitario. $86.6 \%$ of farmers identified birds as the main element of mistletoe dispersal; 93.3\%mentioned that pruning of infected branches is best control for mistletoe. This study has established that three mistletoe parasites infest cocoa plantations in Kumba and determined their incidence, severity and distribution. Phragmanthera lapathifolia was the most abundant parasite and birds were most involved in mistletoe dispersal.
\end{abstract}

Keywords: Cocoa, Mistletoe Infestation, Yield Loss, Parasitic Plant, Diversity, Severity

\section{Introduction}

Cocoa, Theobroma cacao of the Malvaceae is an evergreen, perennial tree grown by small holder farmers for its seed (beans) which are used primarily in the manufacture of chocolate [1]. It is one of the main export crop of Cameroon and a major source of income to the rural farm families [2]. Since its introduction by the Germans in 1892 [3], it is now cultivated by more than 400,000 farmers on at least 400,000 ha [4]. The crop has enormous potentials as the beans contain carbohydrates, fats, proteins, natural minerals such as magnesium, sodium, calcium, iron, phosphorous and zinc and vitamins including thiamine, riboflavin and niacin [5]. Like several other plant foods such as tea, red wine, fruits, vegetables and nuts, cocoa contains a group of compounds which exhibit health benefits, although these may be affected by fermentation and processing [6]. Cocoa is used in the manufacturing of chocolate and chocolate drinks, cacao butter is used by the pharmaceutical industry for coating pills and suppositories, some herb shops and 
pharmacies supply cacao seed shells that are sold as diuretic tea [7]. When compared to other agricultural activities, this tree crop has been a leading sub-sector in the economic growth and development of Cameroon which is $5^{\text {th }}$ in world production and $4^{\text {th }}$ in West Africa that produces $70 \%$ of the world's total of 3.2 million tons. Cote D'Ivoire produces (40\%), Ghana (15\%), Nigeria (5\%) and Cameroon (5\%) [8]. But recently, the system has been under threat due to diseases that include: Cocoa swollen shoot virus, black pod and witches' broom; pests like cocoa pod borer, and mirids and other pests of increasing importance such as the parasitic plants (mistletoe). All of these account for about 30\% of yield loss in cocoa farms [9].
Research on parasitism of mistletoe on cocoa had been ongoing in several countries like Côte d'Ivoire, Ghana, Nigeria, Brazil, Colombia, and Mexico but only scanty work on these parasites had been undertaken on cocoa in Cameroon especially in the South West Region and Kumba Municipal Council Area in particular which is the major cocoa production hub in the region [10]. In order to elaborate on the strategies to control parasitism of mistletoe on cocoa trees, there is need to identify mistletoe species infecting cocoa plants in the Kumba locality, Southwest Region, Cameroon, determine their prevalence, incidence, severity and distribution and to have baseline information from cocoa farmers onpossible sources of infection and spread.

\section{Materials and Methods}

Description of the study area

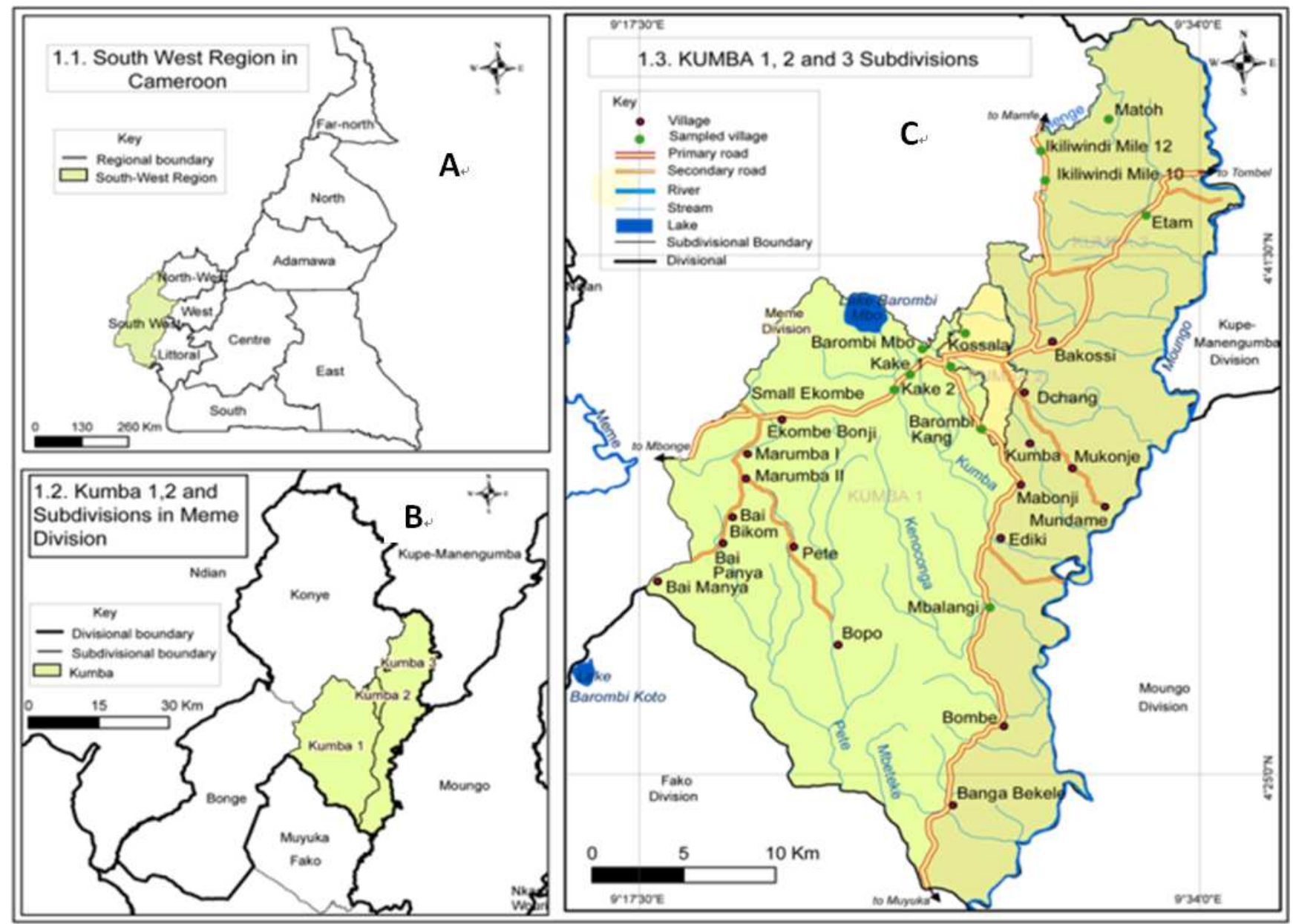

Source: Department of Town Planning/ Kumba Urban Council, 2005

Figure 1. A = Map of Cameroon; B = Map of Meme Division; $C=$ Map of the Kumba Council Area showing villages where survey was carried out.

The study was carried out in 10 villages of the Kumba Municipal Council Area that include Barombi-Mbo, Barombi-Kang, Bekondo, Ekombe, Ikiliwindi, Kake I, Kake II, Kossala, Matoh, and Etam II (Figure 1). Kumba is a road junction town of the South West Region of Cameroon located between latitudes $9^{\circ} 25^{\prime}$ and $10^{\circ} 28^{\prime}$ North of the equator and between longitudes $4^{\circ} 37^{\prime \prime}$ and $6^{\circ} 35^{\prime \prime}$ East of the Greenwich Meridian [11]. It is bounded in the North by Mbonge, South by Ekombe, East by Balondu and West by Mukonje. This town is located on the leeward side of Mount Cameroon at $220 \mathrm{~m}$ above sea level and Mount Barombi-Mbo that is $467 \mathrm{~m}$ above sea level. The climate is 
equatorial with annual rainfall ranges between $2500 \mathrm{~mm}$ $3250 \mathrm{~mm}$ per annum. The town is located in the monomodal humid forest agro-ecological zone marked by two distinct seasons; a long rainy extending from March to November and a short dry season of three months (December to February). Climate is suitable for rubber, oil palm and cocoa cultivation [12]. Soils in this area are mainly volcanic, characterized by soft black, red, stony, and sandy which are heavily leached during rains. This fertile soil with $\mathrm{pH}$ of 5.0 is responsible for the higher yields of cultivated crops. The relief of Kumba is characterized mostly by mountains and plains that are polyconcave and polyconvex in nature though this is mostly seen along the hills close to the lake Barombi and also along the central portion of the slopes close to the Kumba river. The area itself is a natural inland plane which stretches from the Northern Rumpy hills and extends to the Southward slopes reaching the Bakundu hills. These hills lie along the mount Cameroon volcanic line which stretches from Equatorial Guinea at the Atlantic Ocean and extending to Buea, KupeMwanenguba area and finally reaching Northwestern Highlands of Cameroon. Lake Barombi-Mbo falls between an active seismic zone. The various plains in Kumba include the Mambugisse plain which stands broadly to occupy the Eastern section of Kumba while the Njinkindi plain lie as a Pedi plain close to the leeward hills. Along the Northern slopes most especially close to the primary rainforest lies an igneous escarpment spreading to encircle the Lake Baroumbi-Mbo.

\subsection{Method}

\subsubsection{Model Specification}

This study was based on the conceptual models that considered a baseline situation where there is no pest occurrence and assumes the implementation of Best Management Practices (BMP) in cocoa farming.

\subsubsection{Study Design}

The first step was to carry out a field survey which involved mistletoe identification in 30 farms in the 10 villages 3 farms/village) and the second step was to administer questionnaires to cocoa farmers from both genders. This was followed by sampling population, data collection, data analysis, results and discussions/conclusions.

\subsubsection{Field Survey for Plant Sample Collection and Identification}

Thirty cocoa farms of size between 1-1.5 ha were surveyed for mistletoe infestation in 10 villages of Kumba. This was done from May-August 2018 where 220 plants were examined within a line transect. For each tree examined, symptomatic tree branches, the leaves, stem, flowers and bark of parasitic species seen on cocoa plants were collected separately and plant pressed in triplicates. Each sample was labeled and geo-referenced before being taken to the Limbe Botanic Gardens for proper identification of the species of mistletoe. Information was also recorded for each cocoa tree of the type of mistletoe, number of branches affected, cocoa variety, age of the plant and the total number of branches on each tree.

Field identification of mistletoe species, determination of their abundance, incidence, severity and distribution within the Kumba localities was noted. Qualitative and quantitative description methods were used to clarify concepts, characteristics, descriptions and counting of cocoa trees in farmers' fields.

Disease incidence for each field was calculated as described by [13], using the formula:

\footnotetext{
$\%$ incidence $=$ number of plants with mistletoe infestation/ Total number of plants in each field expressed as a percentage
}

Abundance $=$ Number of each parasite in the field/ Total number of parasites, expressed as a percentage

$\%$ Disease severity $=[(\mathrm{P} \times \mathrm{Q}) /(\mathrm{M} \times \mathrm{N})] \mathrm{X} 100: \mathrm{P}=$ severity score, $\mathrm{Q}=$ number of infected plants with the same score,

$$
\mathrm{M}=\text { total number of plants examined and } \mathrm{N}=\text { maximum rating number }
$$

In order to have farmers' perspectives on the mode of dispersal and the control strategies used, 60 cocoa farmers were interviewed. Male and female of both age ranges between 25 and 60 were selected based on multi-staged sampling method.

In the first stage, 10 of the 60 farmers in the Kumba locality that included Kake 1, Barombi-Mbo, Ikiliwindi, Matoh and Etam II were selected based on availability (convenience) and in the second stage, some representatives of the Ministry of Agriculture and Rural Development were identified so as to know those farmers involved in cocoa production and thirdly, three heads of farmers Common Initiative Groups (CIG) were identified and other farmers who did not belong to any CIG.

Data was obtained from a semi-structured questionnaire with open ended questions and respondent's socio- demographic characteristics. A total of 60 questionnaires/ responses were obtained at the end of the exercise as no inquiry was rejected. Field visits were made alongside to collect information on the state of mistletoe infestation in cocoa fields and their control measures. To ensure reliability of data collected, instruments pre-testing were done. Here, questionnaires were pre-tested in Kake I and at the end, some questions were added, others modified or re-phrased to reduce ambiguity making the final chosen variables to be directly related to the objectives of this study. Validity of data collected was ensured by face-to-face administration of the questionnaires so that vague or misunderstood questions were clarified.

\subsection{Data Analysis}


Microsoft Excel software 17 was used to analyze the data and analysis of variance was used to compare averages and variances in the studied plots. Tables and graphs were used in the presentation of results. Data obtained from the questionnaires were analyzed using descriptive statistics (tables, frequencies, percentages) while qualitative data obtained from semi-structured interviews were analyzed and reported thematically.

\section{Results}

Field Survey for Plant Parasite Sample Collection and Identification

Three mistletoe species were identified from voucher specimens taken to the Limbe Botanic Gardens and they include; Phragmanthera lapathifolia, Phragmanthera batangae and Tapinanthus globiferous (Figure 2).
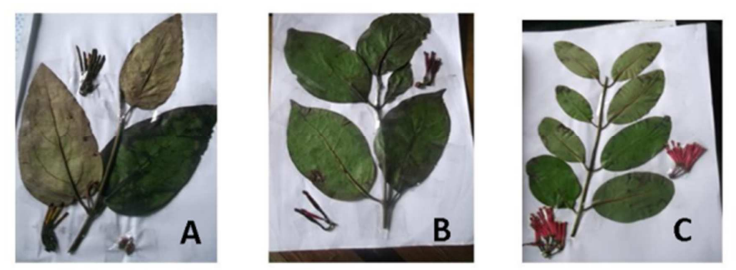

Figure 2. Leaf Pressed Mistletoe species specimens infecting cocoa plants collected from farmers' fields in the Kumba locality. $A=$ Phragmenthera lapathifolia; $B=$ Phragmenthera batangae and $C=$ Tapinanthus globiferous).

Characteristic symptoms of the three mistletoe species identified in cocoa farms in the Kumba locality

Figure 3 shows the characteristic symptoms exhibited by the mistletoe. Phragmanthera lapathifolia. It had red corolla tips whereas Phragmanthera batangae had bright green broadly ovate or ovate-lanceolate leaves. The third species, Tapinanthus globiferusis a woody spreading shrub with blackish, smooth stems made rough by the presence of lenticels. The leaves are opposite but sometimes alternate.
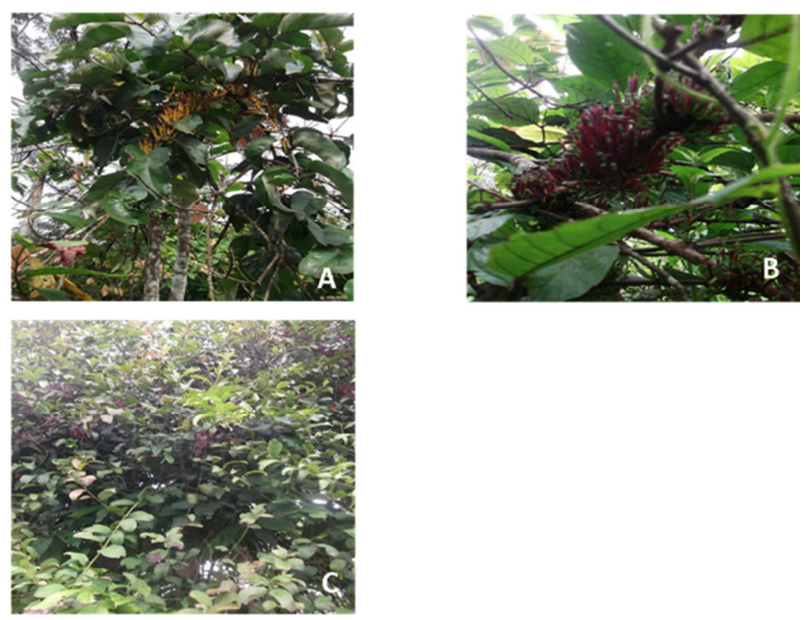

Figure 3. Different species of mistletoe infecting cocoaidentified in farmers fields in Kumba Municipal Council Area showing their characteristic symptoms.

Incidence of mistletoe infestation in farmers' fields in

\section{Kumba Council Area}

Out of the 7,279 cocoa trees examined, 2,290 representing $31.46 \%$ were infected with one or more mistletoe species and of the 10 villages, Kake I had the high incidence of mistletoe (43.11\%), followed by Etam II (38.34\%) and Barombi-Mbo the lowest with incidence of $10.58 \%$ (Table 1 ).

Abundance and severity of mistletoe infection on cocoa in farmers' fields in ten villages in Kumba Council Area

Table 2 shows that the highest abundance of mistletoe species on cocoa in this study was P. lapathifolia $(68.12 \%)$ and the least was $P$. batangae (4.9\%).

Severity score rating in farms of the 10 villages varied. Kake Ihad mistletoe infected plants with the highest severity score of 4 followed by Kossala II and Barombi-Mbo had the least (Table 3).

Susceptibility rating of mistletoe infection on cocoa varieties in farmers' fields in Kumba Municipal Council Area.

Table 4 highlights the analysis of variance done to compare the mean susceptibility rating of two cocoa varieties (Forastero and Trinatario) grown in the Kumba locality shows that they were significantly different in susceptibility to mistletoe both at $\mathrm{P}=0.05$ and $\mathrm{P}=0.01$. The Forastero variety was more susceptible to the plant parasite than the Trinatario.

Distribution of the mistletoe species in farmers' fields in Kumba Council Area

Out of 7,279 cocoa plants examined during this survey 2,290 were infected with any of the three parasites. 1,560 representing $21.43 \%$ were infected with Phragmanthera lapathifolia, 112 representing 1.53\% with Phragmanthera batangae and 618 representing $8.4 \%$ with Tapinanthus globiferus. Kake 1 had the highest infection with Phragmanthera lapathifolia (9.25\%), while Etam 11 had more of Phragmenthera batangae than any other village cocoa farm $(8.51 \%)$. There was no occurrence of Phragmenthera batangae in Barombi-Mbo (Table 5).

Mixed infection of mistletoe species on cocoa in farmers' fields in the Kumba Municipal Council Area.

Table 6 shows that out of the ten villages examined, Kake 1 and Barombi-kang had the highest number of parasite species per plant (3 parasites) followed by Kake II, Kossala II, Etam II, Small-Ekombe and Ikiliwindi with two (Phragmanthera lapathifolia and Tapinanthus globiferus). Cocoa farms in Barombi-Mbo were infected with just Phragmanthera lapathifolia

Demographic characteristics of respondents (cocoa farmers) in the Kumba Municipal Council Area.

Figure 4 presents gender distribution of cocoa farmers in the Kumba Municipal Council Area, where 13.3\% (8 out of 60 ) of the farmers were female and $86.7 \%$ male while in Figure 5, the bar chart shows the age group distribution of cocoa farmers. Most of them are between the ages of 36-55 with 21 out of 60 between the ages of 36-45 and just 9 out of 60 were above 55 years of age.

Response of farmers on the mode of dispersal of mistletoe seeds and management of mistletoe on cocoa in farmers' fields in Kumba Municipal Council Area.

$86.7 \%$ of farmers in Kumba believed that birds are the 
principal agents of dispersal of these parasites while $13.3 \%$ reported mechanical injuries from pruning machetes (Table 7).

Table 8 shows that pruning of mistletoe infected cocoa tree branches was the method used by most farmers in managing the parasite (93.3\%). Most farmers suggested that scaring away of birds and cleaning of pruning knives will control the spread of mistletoe in their farms.

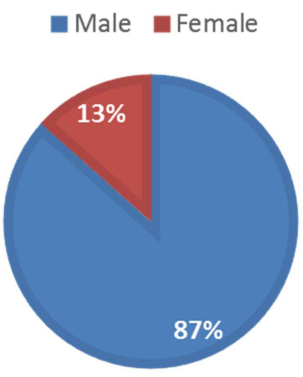

Figure 4. Demographic representation of the gender value of cocoa farmers in the Kumba locality.

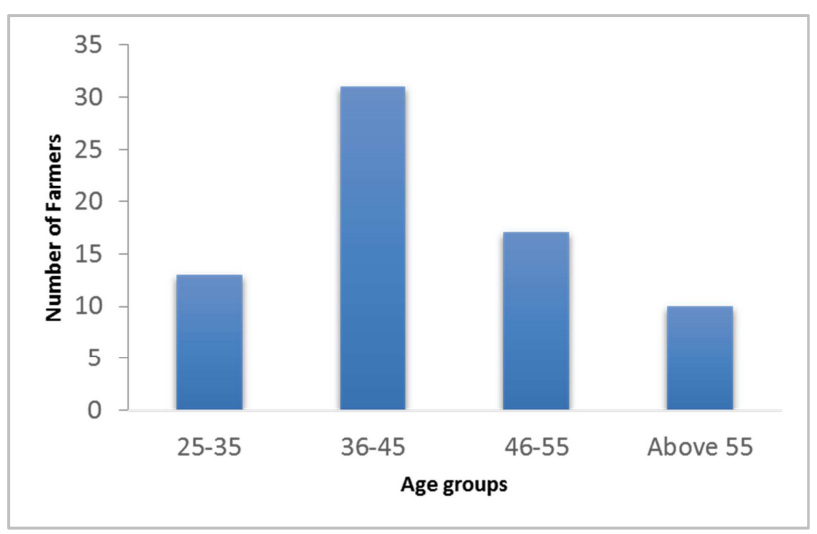

Figure 5. Age range groupings of cocoa farmers in the Kumba Municipal Council Area.

About $57 \%$ farmers in Kumba believe that mistletoe infestation on coca reduce yield, $37 \%$ speculated cocoa tree death while $6 \%$ assumed that infestation of mistletoe in their fields result to stunted growth of their plants (Table 9).

Table 1. Incidence of mistletoe infestation on cocoa in farmers'fields in the Kumba Municipal Council Area.

\begin{tabular}{|c|c|c|c|c|}
\hline Farm Location & No. of cocoa trees surveyed & No. of Uninfected cocoa trees & No. of Infected cocoa trees & $\%$ Incidence \\
\hline Barombi-kang & 737 & 523 & 213 & 29.04 \\
\hline Barombi-Mbo & 775 & 693 & 82 & 10.58 \\
\hline Bekondo & 771 & 554 & 197 & 35.55 \\
\hline Kake 1 & 726 & 413 & 313 & 43.11 \\
\hline Kake 2 & 698 & 437 & 261 & 37.39 \\
\hline Kossala 2 & 715 & 476 & 259 & 33.42 \\
\hline Small-Ekombe & 688 & 449 & 239 & 34.74 \\
\hline Etam 2 & 759 & 468 & 291 & 38.34 \\
\hline Total & 7,279 & 4,988 & 2,290 & 45.91 \\
\hline
\end{tabular}

Table 2. Abundanceof mistletoe infection in cocoa farmers' fields in Kumba council area

\begin{tabular}{lll}
\hline Species of Loranthceae & Number of parasites & \% abundance \\
\hline Phragmanthera lapathifolia & 1560 & 68.12 \\
Phragmanthera batangae & 112 & 4.9 \\
Tapinanthus globiferus & 618 & 26.98 \\
Total & 2290 & 100 \\
\hline
\end{tabular}

Table 3. Severity rating of mistletoe infection on cocoa in farmers' fields in the Kumba Municipal Council Area.

\begin{tabular}{llll}
\hline Location & Number of farms & Infected plants & Mean severity \\
\hline Barombi-kang & 3 & 213 & 3 \\
Barombi-Mbo & 3 & 82 & 1 \\
Bekondo & 3 & 197 & 2 \\
Ikiliwindi & 3 & 244 & 3 \\
Kake I & 3 & 313 & 4 \\
Kake 2 & 3 & 261 & 2 \\
Kossala 2 & 3 & 259 & 3 \\
Matoh & 3 & 191 & 2 \\
Small-Ekombe & 3 & 239 & 2 \\
Etam II & 3 & 291 & 3 \\
Total & 30 & 2,290 & 2.4 \\
\hline
\end{tabular}

Table 4. Susceptibility rating of mistletoe infection on the two cocoa varieties plantedin Kumba Council Area.

\begin{tabular}{lllll}
\hline Variety & Number & Mean & StDev & $\boldsymbol{F}$-Value \\
\hline Forastero & 19 & 41.39 & 13.94 & 25.42 \\
Trinatario & 11 & 16.03 & 12.00 & $P=.05$ \\
\hline
\end{tabular}

Pooled StDev $=13,2793$ 
Table 5. Distribution ofmistletoespecieson cocoa in farmers'fields in Kumba Municipal Council Area.

\begin{tabular}{lllll}
\hline Location & PI & Pb & Tg & Total \\
\hline Barombi-kang & 133 & 11 & 69 & 213 \\
Barombi-Mbo & 58 & 0 & 24 & 82 \\
Bekondo & 143 & 9 & 45 & 197 \\
Ikiliwindi & 179 & 12 & 53 & 244 \\
Kake I & 212 & 9 & 92 & 30 \\
Kake II & 158 & 23 & 72 & 261 \\
Kossala II & 174 & 13 & 43 & 259 \\
Matoh & 133 & 15 & 55 & 191 \\
Small-Ekombe & 175 & 9 & 85 & 239 \\
Etam II & 195 & 11 & 291 \\
Total & 1560 & 112 & 290 \\
\hline
\end{tabular}

Pl: Phragmanthera lapathifolia; Pb: Phragmanthera batangae; Tg: Tapinanthus globiferus

Table 6. Mixed infection of mistletoe in cocoa farms in villages of the Kumba Municipal Council Area.

\begin{tabular}{lll}
\hline Location & Mean number of parasites/plants & Type of mistletoe \\
\hline Barombi-kang & 03 & $P . l ; P . b$, and $T . g$ \\
Barombi-Mbo & 01 & $P . l$ \\
Bekondo & 02 & $P . l$ and T.g \\
Ikiliwindi & 02 & $P . l$ and T.g \\
Kake I & 03 & $P . l, P . b$ and T. $g$ \\
Kake II & 02 & $P . b$, and T. $g$ \\
Kossala II & 02 & $P . l$ and T.g \\
Matoh & 02 & $P . b$ and T.g \\
Small-Ekombe & 02 & $P . l$ and T.g \\
Etam II & 02 & $P . l$. and T.g \\
\hline
\end{tabular}

Pl: Phragmantheralapathifolia; Pb: Phragmantherabatangae; Tg: Tapinanthusglobiferus

Table 7. Response of farmers on the mode of dispersal of mistletoe in cocoa farms in Kumba Council Area.

\begin{tabular}{lll}
\hline Mode of dispersal & Number of farmers & Percentage \\
\hline Birds & 52 & 86.67 \\
Pruning equipment & 08 & 13.33 \\
Wind & 00 & 00 \\
Insects & 00 & 00 \\
Total & 60 & 100 \\
\hline
\end{tabular}

Table 8. Response of farmers to methods of controlling mistletoe on cocoa trees in Kumba Council Area.

\begin{tabular}{lll}
\hline Method & Number of cocoa farmers & Percentage of cocoa farmers (\%) \\
\hline Mechanical (standard pruner) & 04 & 6.67 \\
Mechanical (machete) for pruning infected branches & 56 & 93.3 \\
Chemical control & 00 & 00 \\
Biological control & 00 & 00 \\
Shade management & 00 & 00 \\
Total & 60 & 100 \\
\hline
\end{tabular}

Table 9. Response of farmers on the effect of mistletoe damage on cocoa farms in Kumba Municipal Council Area.

\begin{tabular}{lll}
\hline Damage & Number of farmers & Percentage (\%) \\
\hline Stunted growth & 04 & 6.33 \\
Mortality & 22 & 36.67 \\
Reduced yield & 34 & 56.67 \\
Total & 60 & 100 \\
\hline
\end{tabular}

\section{Discussion}

The demographic structure of farmers in Kumba locality showed that very few women were involved in cocoa farming when compared to men $(13.3 \%)$. This is because cultural implications in this area do not permit women to own fixed assets like farmland and also, even if they have to farm, crops grown should be limited to only subsistent staple crops mainly for home consumption or at least to sell part of it in the local markets. Those who somehow own cocoa farms may have inherited them from their late husbands or as compensation from debt recovery. The few number of young men involved in cocoa farming in this area is because most young men take part only in the production chain like transportation of the harvested produce to the sale points in the villages, processing and even marketing. They often lack the highly needed financial strength to acquire farmlands and cover the cost of establishing a cocoa farm. Also, youths nowadays are more attracted to secondary and tertiary occupations.

All 30 fields assessed had incidence of mistletoe infestation with percentage incidence ranging from $10-43 \%$. 
The level of infestation was also very high in the cocoa producing villages with mean severity scores ranging between 1 and 3 on a $0-5$ scale. Kake I had the highest incidence of mistletoe infestation with a mean severity scoring of 3 . This indicates that the parasites are highly prevalent in the area and the infection level is very severe, suggesting that the parasite is a serious threat on the growth and yield of the cocoa plant. This high severity can be attributed to regeneration of mistletoe on cocoa trees, the presence of alternate hosts as most farms are mixedly planted with the African plum (Dacryodes edulis) and citrus which are known for hosting the parasite. This finding agrees with the report by [14], who stated that cocoa is the most parasited plant by mistletoe among 10 cultivated and spontaneous fruit plants in Cameroon. Six out of the identified seven Loranthaceae species known in the country attacked cocoa plants. An urgent control of the parasite is needed in order to save the cocoa industry and to reduce poverty levels among cocoa farmers in Cameroon.

Out of the 7,279 plants assessed, 2290 were infested with one or more mistletoe species and this is having a devastating effect on cocoa production. This rate of mistletoe infestation on tree plants and cocoa inclusive has been attributed to several factors by [15]. Among them spatial arrangement of the cocoa trees was the most important in explaining mistletoe density. The study revealed that farms planted randomly had significant higher infection rate of the parasite than those planted in rows. This was the case in the Kumba locality where many of the farms were planted haphazardly and even those that were initially planted in rows, over the years have lost the alignment because dead plants were not replaced thereby creating ample space for attack by vectors and conducive environment for their establishment. [16] reported that incorporating shade trees in cocoa agro-forest is the key mitigating measure against mistletoe infestation across cocoa growing countries in West Africa. They recommended 15-18 shade trees/ hectare as it provides 30$40 \%$ canopy cover that limits germination and establishment of Tipananthus bangwensis, a Loranthaceae.

In this study, Phragmanthera lapathifolia was the most abundant mistletoe species infecting 1560 out of the 2290 plants followed by Tapinanthus globiferus. This result was similar to that of [10] where both parasites were the most abundant species infesting cultivated tree crops and those that grew spontaneously in the Douala localities of Cameroon. Their distribution according to [17] coincided with that of host trees. This report revealed that host availability and spatial arrangement as the most important factors in mistletoe distribution within a landscape. Spatial arrangement of cocoa regulates farm visibility, tree density, shade coverage and farm humidity implying that far away trees are less likely to be infected than the close ones. It further stated that occurrence of mistletoe on host trees, correlates with individual tree characteristics such as age of the tree, farm size and variety of cocoa. Similarly, [16] reported that host distribution, size and sex are pertinent factors influencing mistletoe distribution and abundance. They stated that when hosts are scattered, their mistletoe parasites maybe less common and widely distributed as well as birds that disseminate often perch at the larger trees thus depositing mistletoe seeds high in the canopy. This study further revealed that for dioecious species, birds' visitation can be biased in favour of fruiting plants thereby influencing the overall mistletoe distribution and also, the consistent availability of mistletoe fruits can attract birds which feed on host fruits as well thereby, spreading seeds from infected to non-infected hosts. Other agro-ecological factors such as diversity of shade trees and density are important factors that influence mistletoe occurrence and distribution.

Cocoa farmers in the Kumba locality believed that birds are the most important agents of dispersal of mistletoe $(86.6 \%)$ while $13.3 \%$ said that it was dispersed by pruning machetes. The study agrees with report by [18] that birds are the most important agents of dispersal. The report further highlighted that birds are responsible for long distant dispersal. The spread of mistletoe by pruning equipment is supported by [19] who reported that harvesting tools and pruners are carried from infested to healthy trees during harvesting and pruning operations. Some other authors including [20] and [15], reported that 90 bird species from 10 families are mistletoe fruit specialist since they are attracted to the brightly coloured fruits having seeds that are coated naturally with a sticky substance called viscin. When these seeds are swallowed wholly or partly after peeling off the external exocarp, they are defecated or regurgitated and because they are still covered with viscin, they easily get adhered to any host. Other agents of mistletoe dispersal include rodents such as the marcupial and squirrels [21], by wind after fruit dehiscence and seed rain from higher canopies [19].

About $93 \%$ of farmers employed mechanical means of parasite control by cutting the mistletoe from the infested cocoa plant using machete. But because most of the cocoa plants are tall coupled with the age of the farmers, climbing of the trees to remove infested branches was not possible and also, regeneration of the mistletoe after cutting was another challenge to the farmers in managing the parasite on cocoa. It had been recommended by [21] that branches should be cut at least $30 \mathrm{~cm}$ below the point of attachment of the mistletoe to ensure the removal of the haustoria that extends up and down the branches to prevent its regeneration. These authors made further recommendations that include planting of canopy trees known to be resistant to mistletoe infestation like the conifers, eucalyptus and cedar, the use of growth regulators like ethephon for temporal control, removal of severely infested plants, replacement with less susceptible species and covering with an opaque material the points where mistletoe has been removed and integrated pest management requiring all stakeholders in the community to sanitize their fields and gardens.

\section{Conclusion}

Three mistletoe species were identified in cocoa fields in the Kumba locality and Kake I was the most infected village 
having all the identified types. The presence of mistletoe species on cocoa in the Kumba locality is a cause for concern especially with the high incidence and severity which results to growth reduction, yield loss and cocoa plant mortality. There is need to educate farmers on the best and updated practices for the control of these parasites from their fields. It is recommended that the government of Cameroon through the Ministry of Agriculture and Rural Development make available to the farmers qualified extension agents to educate them on measures of managing these parasites on cocoa and also provide standard pruners for use in cutting infested parts of the cocoa plants. Resistant cocoa varieties should be planted in order to reduce the severity of these parasites.

\section{Acknowledgements}

We thank the cocoa farmers in the 10 villages and their traditional council. We are also grateful to workers of the Divisional Delegation of Agriculture in Kumba Council Area for their assistance and collaboration during this study.

\section{References}

[1] Adejumo TO 2015 Crop protection strategies for major diseases of cocoa, coffee and cashew. African Journal of Biotechnology 4: 143-150.

[2] Bentley JW, E Boa, J Stonehouse 2004 Neighbour trees: shade, intercropping and cocoa in Equador. Human Ecology 32: $241-270$.

[3] Belskey JM, SF Siebert 2003 Cultivating cacao: implications of sun-grown cacao on local food security and environmental sustainability. Agriculture and Human Values 20: 277-285.

[4] Ngoe M, Z Li, M Beckline, P Bobyeg 2018 Cocoa production in Cameroon: a socioeconomic and technical efficiency perspective. International Journal of Agricultural Economics 3: $1-8$.

[5] Torres-Moreno M, E Tonrescasana, JS Salas, C Blanch 2015 Nutritional composition and fatty acid profile in cocoa beans and chocolate with different geographical origin and processing conditions. Journal of Food Chemistry 166: 125132.

[6] Apriyanto M, S Sutardi, H Eni 2016 Study of the effect of fermentation to the quality parameter of cocoa bean in Indonesia. Asian Journal of Dairy, Food Research 35: 160163.

[7] Dan-Ju, M Gertrand 2016 Cocoa-pests, medicinal uses, current scientific evidence and advertised health benefit. Elsevier Academic Press.

[8] Hebbar-Prakash PK 2007 Cocoa diseases. A global perspective from an industry point of view. Phytopathology 97: 1658-166.
[9] Andreas C, A Gattinger, HK Dzahini-Obiattey, WJ Blaiser, SK Offei, J Six 2017 Combatting cocoa swollen shoot disease. What do we know? Crop Protection 98: 76-84.

[10] Assonwa FE 2015 An assessment of pests and disease management on cocoa production: case study of EkondoTiti, Ndian Division, Cameroon. MSc diss. Pan African Institute of Development, Buea, Cameroon.

[11] Nkobe M, S Molua, J Armathee, S Ayonghe 2013 Impact of climate change and climate variability on cocoa (Theobromae cacao) yields in Meme Division, South West Region, Cameron. Journal of Cameroon Academy of Sciences 11: 11-19.

[12] Kotto-Same J, LW Paul, A Moukam, L Zapfack 1997 Carbon dynamics in slash and agriculture and land use alternatives of the humid forest zone in Cameroon. Agriculture, Ecosystem and Environment 65: 245-256.

[13] Oben TT, JD’A Hughes, TE Njock, R Hanna, PL Kumar 2015 Survey of occurrence and identification of viruses infecting Musa species in Cameroon. International Journal of Current Microbiology and Applied Sciences 4: 502-511.

[14] Dibong SD, Z Ndiang, R Mony, I Boussim, A Joseph 2010 A parasitic study of Phragmanthera capitata (Sprengel) S. Balle (Loranthaceae) in the anthropic environments: the case of the Ndogbong chieftain's compound orchard (Douala, Cameroon). African Journal of Agricultural Research 5: 2051 - 2055.

[15] Mathasien LR, D Robert, L Nikrent, DC Shaw, DM Watson 2008 Pathology, systematics, ecology and management. American Phytopathological Society. Plant Disease 92: 9861005.

[16] Smith DE, GM Gnahoua, F Sinclair, P Vgast 2014 Farmers in Cote d'Ivoire value integrating tree diversity on cocoa for the provision of ecosystem services. Agroforest Systems 88: 1047-1066.

[17] Arce-Costa I, A Susan, O Garcia-Rubio 2016 Biotic factors associated with spatial distribution of mistletoe, Psittacanthus calyculatus in a tropical deciduous forest of Central Mexico. Botanical Science 94: 89-96.

[18] Asare-Bediako E, AA Addo-Quaye, JP Tetteh, JN Buah, GC Van Der Puije, RA Acheampong 2013 Prevalence of Mistletoe on Citrus Trees in the Abura-Asebu- kwamankese District of the Central Region of Ghana. International Journal of Scientific and Technology Research 2: 122-127.

[19] Shaw C, Watson DM 2008 Pathology, systemics, ecology and management. American Phytopathological Society. Plant disease 92: 988-1006.

[20] Adam K, DW Green, EG Morgan 2009 Direct dispersal of mistletoe (Plicosepalus acacia) by Yellow-Vent Bulbuls (Pycnonotus xanthopygus). Journal of Ornithology 150: 167173.

[21] Guillermo C, M Amoco, A. Aizen 2020 Marsupial (Dromiciops australis) endemic to this region-a task previously thought to be carried out exclusively by birds. Nature 408: 929-930. 